\title{
Article
}

\section{A New Design Procedure for Rotor Laminations of Synchronous Reluctance Machines with Fluid Shaped Barriers ${ }^{\dagger}$}

\author{
Federica Uberti ${ }^{1}$, Lucia Frosini ${ }^{2, *(\mathbb{D})}$ and Loránd Szabó ${ }^{3}(\mathbb{D}$ \\ Terna Rete Italia SpA, 20016 Pero, Italy; federica.uberti@terna.it \\ 2 Department of Electrical, Computer and Biomedical Engineering, University of Pavia, 27100 Pavia, Italy \\ 3 Department of Electrical Machines and Drives, Technical University of Cluj-Napoca, 400114 Cluj-Napoca, \\ Romania; Lorand.Szabo@emd.utcluj.ro \\ * Correspondence: lucia.frosini@unipv.it \\ $+\quad$ This paper is an extended version of our paper "An Optimization Procedure for a Synchronous Reluctance \\ Machine with Fluid Shaped Flux Barriers" published in 2020 International Conference on Electrical \\ Machines (ICEM).
}

check for

updates

Citation: Uberti, F.; Frosini, L.; Szabó,

L. A New Design Procedure for Rotor

Laminations of Synchronous

Reluctance Machines with Fluid

Shaped Barriers. Electronics 2022, 11,

134. https://doi.org/10.3390/

electronics11010134

Academic Editors: Teresa

Orlowska-Kowalska and

Sheldon Williamson

Received: 18 November 2021

Accepted: 30 December 2021

Published: 2 January 2022

Publisher's Note: MDPI stays neutral with regard to jurisdictional claims in published maps and institutional affiliations.

Copyright: (c) 2022 by the authors. Licensee MDPI, Basel, Switzerland. This article is an open access article distributed under the terms and conditions of the Creative Commons Attribution (CC BY) license (https:// creativecommons.org/licenses/by/ $4.0 /)$.

\begin{abstract}
A new procedure for the design and optimization of the rotor laminations of a synchronous reluctance machine is presented in this paper. The configuration of the laminations is symmetrical and contains fluid-shaped barriers. The parametrization principle is used, which executes variations in the lamination geometry by changing the position, thickness and shape of the flux barriers. Hence, the optimization procedure analyzes the various configurations through finite element simulations, by means of the communication between MATLAB and Flux 2D. In the post processing stage, the best geometry which optimizes mean torque, torque ripple, efficiency and power factor is selected. Once the best rotor configuration is defined, further investigations allow improving its performance by modifying the current angle, the stator winding and the thickness of the radial ribs.
\end{abstract}

Keywords: AC machines; design optimization; finite element analysis; numerical simulation; rotating machines; rotors

\section{Introduction}

The scientific and research interest for the Synchronous Reluctance Machine (SynRM) has grown in the last ten years thanks to its superior performance in terms of efficiency compared to the induction machine, and its distinctive characteristics of a rotor without permanent magnets in it. These two features make SynRM possibly the best solution to meet high efficiency requirements without the additional costs and volatility of rare-earth permanent magnets. Another advantage is given by the little heat generated by the rotor, due to lack of winding, with consequent very low rotor losses and therefore, good thermal management [1]. Moreover, SynRM offers a good torque density and a wide range of operating speeds [2].

Although this machine has been known since 1923 [3], its modern structure dates back to the nineties, once associated with the use of electronic converters [4-7]. Despite the aforementioned positive characteristics, SynRM has two major drawbacks: a relative high torque ripple and a low power factor. These are the reasons why, starting from about 1990, several researches have concentrated on its design, with the aim of reducing the torque ripple and increasing the power factor.

Indeed, even though the research effort of the past three decades in this field and the introduction of commercial products by major machine manufacturers, a standard procedure for the design of SynRM has not yet been established. While the stator is like that of a standard induction motor, the rotor geometry is unconventional and features multiple flux barriers. Many configurations can be defined in terms of number, shape and size of barriers [8]. 
In fact, torque density and efficiency of a SynRM are strongly influenced by the rotor topology. Therefore, an optimal SynRM rotor geometry design is highly recommended to reach optimal performance in terms of torque density, efficiency, torque ripple and power factor; all these quantities depend on the saliency ratio, i.e., the ratio between direct and quadrature axis inductances $\left(L_{d}\right.$ and $\left.L_{q}\right)$.

There are many strategies for obtaining rotor anisotropy, but the one with laminations perpendicular to the shaft, known as Transversally Laminated Anisotropy (TLA), is preferred, because it is easier to fabricate than that with Axially Laminated Anisotropy (ALA) [4]. Its anisotropy is given by the flux barriers, made by punching in the rotor laminations.

The purpose of alternating flux barriers and segments is to channel the flux along the direct axis ( $d$-axis) and inhibit it in the perpendicular direction, along the quadrature axis ( $q$-axis). In this way, the inductances along the $d$-axis and $q$-axis will be very different and this difference is responsible for the torque development. To ensure the mechanical integrity of the rotor, it is generally necessary to leave ferromagnetic ribs inside the barriers, although, in case of low speed machines, these ribs can be avoided. In fact, these ribs represent possible routes in which the flux can pass: this certainly limits the saliency ratio $L_{d} / L_{q}$, which affects the performance of the machine.

The most common barrier shapes can be divided into circular, segmented or fluid shaped ones. The structure of the lamination can be symmetrical or asymmetrical, but many variants have been investigated in the literature, with the aim of optimizing the performance of the SynRM, e.g., in [9-12]. Moreover, several tools have been proposed to automate the design of these barriers.

Starting from the symmetrical structure of the lamination, in $[13,14]$ an optimization tool for the automated design of SynRM was proposed, based on multi-objective genetic optimization and finite-element analysis (FEA). In particular, in [13] two prototypes were experimentally tested, one with three C-shaped barriers per pole (3C) and one with five C-shaped barriers per pole (5C). Their performances are very similar, in terms of developed torque, torque ripple and efficiency. The improved efficiency of the $5 \mathrm{C}$ machine could justify the adoption of this solution, while the simpler geometry of the $3 \mathrm{C}$ could favor the opposite choice from a production point of view. This last conclusion led to the consideration of only the three barriers per pole topology in [14], but with different sequences of shapes (C-, U- and I-shaped), described by a limited set of input variables. The method proposed in [14] was also used in [15], but with four barriers per pole and also evaluating the possible improvement of the power factor in the optimal design of the rotor. In general, when the number of barriers increases, it is easier to achieve a low torque ripple, as suggested in [16], where a number from 10 to 24 slits per pole is evaluated. Nevertheless, in this case, an ALA rotor core is considered, which is not appropriate for mass production by current technologies.

Segmented (or rectangular) flux barriers are often chosen because they simply allow the insertion of permanent magnets, to obtain the so-called Permanent Magnet assisted Synchronous Reluctance Machine (PMa-SynRM). An interesting investigation on this topic is reported in [17], where different configurations with 4 and 5 rectangular barriers per pole are evaluated with the aim to achieve high speed performance and low torque ripple. The investigated rotor geometries are designed by using a method proposed in [18] to minimize torque ripple, which is a generalized form of the technique presented in [6,7]. The different rotor geometries have the same overall iron and air thickness, but various iron and air distribution among different layers. The performance of the machine is evaluated at both base speed and high speed. The latter condition is reached by means of the field weakening method.

For a SynRM, the torque is given by the following equation:

$$
T_{e m}=\frac{3}{2} p\left(L_{d}-L_{q}\right) i_{d} i_{q}
$$


where $p$ is the pole number, $i_{d}$ is the d-axis current and $i_{q}$ the q-axis current. From this relationship, $i_{d}$ and $i_{q}$ should be equal to get maximum torque per ampere (MTPA), which means that the current angle with respect to the $d$-axis should be $45^{\circ}$ for the unsaturated operations. When the magnetic core saturates, the inductances $L_{d}$ and $L_{q}$ suffer from saturation in a different way: $L_{d}$ is more prone to saturate with respect to $L_{q}$, due to the lower magnetic reluctance along the $d$-axis. As a consequence, the saliency ratio $L_{d} / L_{q}$ decreases. Hence, $i_{d}$ is decreased to maintain $L_{d}$ close to its unsaturated value and $i_{q}$ is increased to achieve a higher torque. A current angle greater than $45^{\circ}$ is then applied, according to the saturation level of the core, in order to obtain the MTPA. The simulations reveal that 5 barriers per pole allow reaching higher average output torque at base speed, while 4 barriers give a better high speed power curve.

Beside the circular and segmented shapes, the third main type of barrier is known as "fluid-shaped", as it follows the natural propagation of the stator flux lines in a solid rotor. One of the first documents which considered these barriers is [19], where a design procedure based on the field lines in a solid rotor is presented. The geometry of these barriers is established by the analytical equations of these lines [20]. The fluid shaped configuration is based on the fact that the magnetic flux always follows the path with the least reluctance. The idea is to model the geometry of the barriers to adapt them to the natural path of the flux in the rotor. In this way, the machine performance can be improved, compared to the other designs, since the maximum quantity of magnetic flux can penetrate the rotor. By properly dimensioning the flux barriers thickness through FEA, this rotor topology can achieve competitive-and sometimes better-results if compared to other geometries. In particular, in [21] this fluid barrier geometry has been able to improve the performance achieved in the previous works of the same authors dedicated to the automatic design of SynRM. In [22], a SynRM with this type of rotor was compared with another one that has round flux barriers but the same stator structure. Thus, the results show that the fluid-shaped barriers machine permits to obtain less high frequency harmonics and a slightly higher torque than the other geometry, with a torque ripple reduced by $50 \%$. A further investigation of the same authors has considered a high-speed application which needs the introduction of ribs in the barriers to withstand the centrifugal force [23]. These ribs significantly improve the mechanical behavior. Rotor with fluid shaped barriers provides higher saliency ratio than that with round barriers, so the developed torque is higher. This rotor also was proved to have better mechanical properties.

Further, very recent papers have investigated the potential of SynRM with fluid shaped barriers. In [9] an electromechanical optimization has been presented, based on a compromise between magnetic performance and mechanical integrity of the rotor. It has been shown that if more barriers are used, higher average torque and lower the torque ripple can be achieved. However, this leads to a decrease in the distance between the innermost barrier and the shaft, with a consequent increase in the Von Mises stress along the radial central bridges. The optimized rotor geometries for one or two operating speeds have four flux barriers. A similar configuration (with four fluid shaped barriers per pole) has been considered in $[10,11]$, where an automatic design procedure for SynRM rotors with minimum number of geometric parameters is presented, with the aim to simplify the design generation and reduce the optimization time. Even in [12] four fluid shaped barriers have been considered as a basis for different optimization strategies. With a similar purpose, but specifically for the design of high speed SynRM for electric vehicle applications, a new rotor layout with multiple ribs in different positions with respect to the flux barriers is presented in [24]; this geometry is quite unusual compared to those reported in the literature. The original positioning of the radial ribs is able to preserve the performance of the motor at high speed, enhancing the mechanical integrity of the rotor. This geometry is taken as a reference for comparison in [25], where a design procedure for SynRM is proposed, based on an open-source software (Syr-e) and a commercial software (Motor-CAD). This procedure adopts a standard simplified geometry with circular flux barriers and tangential and radial ribs. The following considerations about the choice of 
a number of poles are reported in [25]: (i) a lower number of poles increases the power factor and the torque, at the cost of higher iron and copper mass; (ii) a higher number of poles increases the frequency related losses (iron and skin-effect losses); (iii) a higher number of poles simplifies the heat extraction with an outer cooling jacket. The rotor configuration obtained with this procedure provides comparable performance than that taken as reference, without optimization algorithm and less computational effort and time.

A different approach for the design of the SynRM rotor is based on an asymmetrical structure. One of the first efforts was reported in [26], with flux barriers asymmetrically designed; in this way, the relative positions between the outer edges of the flux barriers and the teeth do not match. The method is proposed for a four poles SynRM, with two U-shaped barriers per pole. The [27] develops an analytical model in order to study how the torque harmonics depend on the rotor geometry. An effective torque ripple reduction is obtained by designing flux barriers of different geometries, in two distinct ways: (i) by adopting two distinct laminations for the same rotor; (ii) by using a single lamination with flux barriers of different geometries. The second configuration is called "Machaon", because of the form of the flux barriers, that is similar to the two large and two small wings of a that butterfly. The large and small barriers vary alternatively under the neighboring poles. In [28] a new method called "flux barrier shifting" (FBS) is suggested: the rotor asymmetry is achieved by ideally dividing the rotor structure along $d$-axes and shifting the flux barriers belonging to these sectors of calculated angles. With a correct shifting angle, the unwanted harmonics of each portion are in phase opposition and then cancelled. In [29] the FBS method is then modified and generalized to any number of poles.

In [30] a new approach of asymmetrical rotor is described: the studied topologies employ fluid-shaped barriers without radial ribs in order to maximize average torque and minimize torque ripple. Since this choice is very critical for the mechanical strength of the rotor core especially at high speed, epoxy adhesive resin is used to fill the flux barriers. The performance of the proposed solution is certainly satisfactory in terms of efficiency and power density, although the mechanical analysis highlights some critical issues at high speed and the manufacturing process is more complicated. Reference [31] presents another ribless, but symmetrical, rotor structure, with the aim of improving developed torque, power factor and efficiency over conventional SynRM with iron ribs. The role of iron ribs is purely structural. Nevertheless, they act as a short circuit for the flux between the iron islands. The stator current needed to saturate those iron ribs does not give a contribution to the torque production; this leads to a generation of flux leakage that is closing through the rotor iron ribs.

One option to improve torque production is the optimization of the rotor geometry for the highest saliency ratio $L_{d} / L_{q}$ and with the minimum iron ribs thickness. This thickness depends on the rotor size and on the machine speed, in order to assure a safety margin for mechanical strength. In most designs, the minimum thickness of the ribs is restrained not only by mechanical reasons, but also by minimum fabrication tolerances. Normally, ribs thicknesses less than $0.5 \mathrm{~mm}$ are not recommended, regardless of whether the laminations are produced by punching, laser, or electrical discharge machining (EDM) methods [31]. For high-speed applications, it is necessary to consider the increasing of ribs thickness with the speed, and therefore the SynRM has a limit, corresponding to a speed close to $37,500 \mathrm{r} / \mathrm{min}$. Moreover, the greater thickness of the ribs deteriorates the rotor anisotropy and accordingly the power factor [32].

Another asymmetrical rotor was proposed in [33], where the main aim was to reduce the noise, vibration and harshness $(\mathrm{NVH})$. The asymmetrical rotor allows to reach a great benefit in terms of torque ripple if compared with a symmetrical one. Other methods used to reduce torque ripple include control techniques [34], which are not detailed in this paper.

Furthermore, power factor can be improved through the adequate design of the stator winding. All the above-mentioned papers study a traditional integral slot distributed winding (ISDW), while in [35] a fractional slot concentrated winding (FSCW) is also evaluated. Since FSCW exhibits a high leakage flux, specific design considerations are required for 
use in SynRM. Interesting considerations on the stator winding are also described in [36]: in it, the idea of the research starts from the problem of adapting the rated current of a SynRM to that of the inverters available on the market. This paper shows that it is possible to reduce the motor current and increase the power factor by choosing a different number of turns per coil and changing the stack length. These changes are performed with the aim of maintaining the same rated voltage and output power and achieving a better power factor, which leads to lower current and power consumption.

Most of the methods of increasing the power factor are based on the insertion of permanent magnets in the barriers [37], which will not be considered in this paper. Furthermore, the power factor is influenced by the barriers position and by the ribs thickness along the $q$-axis. Their lack implies the reduction of $L_{q}$ and hence a greater ability to block the flux lines along this axis.

In this paper, based on the outcomes from the literature survey mentioned above, the design and optimization of fluid shaped barriers in a symmetrical rotor will be detailed. After defining the stator like that of an induction machine, a procedure for optimizing the rotor configuration was achieved by varying the shape and the thickness of its flux barriers [38]. This was based on MATLAB and Flux 2D [39] co-simulation capable of achieving an imposed performance target.

\section{Materials and Methods}

\subsection{A Novel Method to Define and Optimize a Fluid Shaped Rotor Geometry}

In order to model the geometry of the barriers of a fluid shaped rotor, the following equation can be used, expressing the flux distribution in a solid rotor, obtained by using conformal mapping concept in complex analysis theory and Zhukovski (noted in literature also as Zhukovsky, Joukowsky or Joukowski) airfoil potential function [19]:

$$
r(\theta, C)=R_{\text {shaft }} \cdot \sqrt[p]{\frac{C+\sqrt{C^{2}+4 \sin ^{2}(p \theta)}}{2 \sin (p \theta)}}, 0 \leq \theta \leq \frac{\pi}{p}
$$

where $r$ and $\theta$ are the polar coordinates (radius and polar angle) of each point of the plane from the direct axis ( $d$-axis), $R_{\text {shaft }}$ is the shaft radius, and $p$ is the machine pole pairs number. The variable $C$ is a constant that identifies each single field line:

$$
C=\sin (p \theta) \cdot \frac{\left(\frac{r}{R_{\text {shaft }}}\right)^{2 p}-1}{\left(\frac{r}{R_{\text {shaft }}}\right)^{p}}
$$

By following these flux lines, the edges of the barriers that optimize the machine can be easily determined.

It should be highlighted that the machine shaft is made of a non-magnetic material; since the flux lines cannot be distributed inside the shaft, they undergo a distortion around it. As demonstrated in [20], there is a similarity between the curves obtained from the analytical equations and the flux lines distribution in the solid rotor obtained by means of from the FEA analysis.

Figure 1 shows how the stator flux lines, given by the analytical expression, propagate in the solid rotor, constrained by the external rotor diameter; the plots of the lines are stopped at $1 \mathrm{~mm}$ away from it. In reality, the distribution continues outside the rotor structure too, but it is obviously not considered in the design of the rotor geometry. 


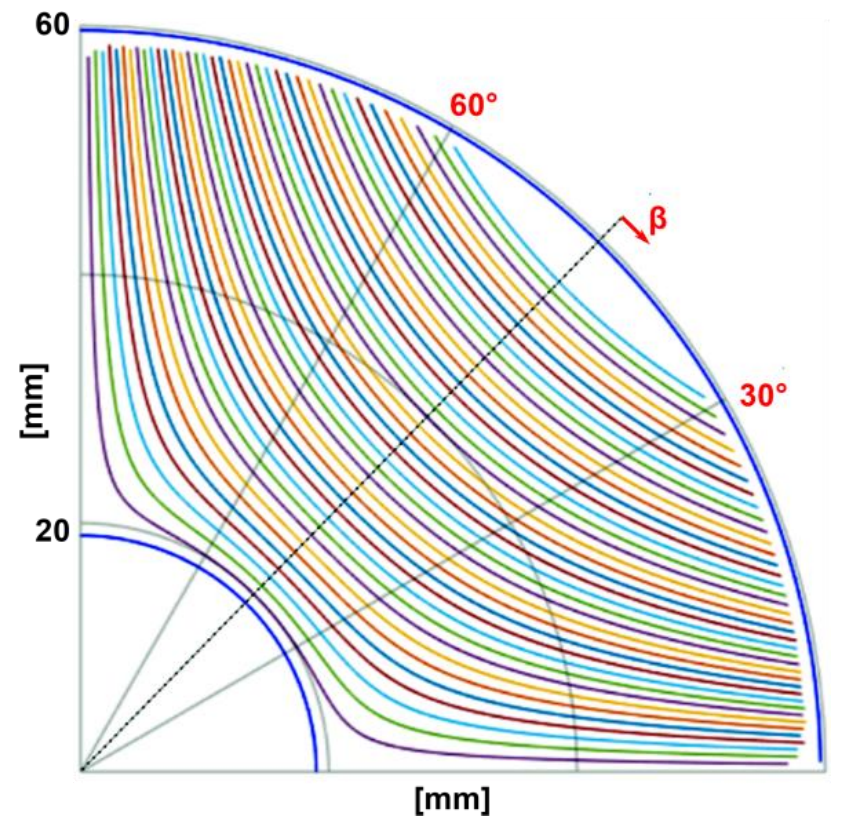

Figure 1. Flux analytical distribution inside the rotor considered in this work.

The lines are defined by introducing an angle $\beta$, measured from the bisector of the first quadrant towards $x$-axis. In particular, in the current work, it is chosen to set it equal to $5^{\circ}$; a value derived from experimental tests. This angle influences another important angle, $\alpha_{m}$, also dependent on flux barriers number $k$, which is used to place the end of each flux barrier:

$$
\alpha_{m}=\frac{\frac{\pi}{2 p}-\beta}{k+\frac{1}{2}}
$$

The new procedure to be presented in this paper has been implemented using various software tools. First, Mathcad was employed for the preliminary sizing. Next, Flux 2D FEA program and MATLAB co-simulation [40] were used to analyze how changes in rotor geometry parameters affects the SynRM performance and to find the best configuration. Finally, the resulting 3D motor structure was drawn by using ANSYS.

The procedure core was based on the coupling between MATLAB and Flux 2D. It was very simple to vary several parameters simultaneously in MATLAB and perform FEA via Flux 2D for numerous configuration variations. First, a table was set up in MATLAB, including all the parameters that define the internal rotor geometry, and also the limits within they can vary. By using a specific code, these data were transferred to Flux 2D, where a Python script was applied to generate the given motor geometry. By applying an iterative process, all possible topologies within the given conditions were taken into account, and FEA was performed for all of them. This calculation process was automatically executed, but it took a long time, since numerous simulations had to be performed.

Even if the applied optimization is a brute force one, it is possible to lower the number of geometric variants considered, and intrinsically the overall simulation times. Some extra geometrical constraints were therefore imposed in order to remove the geometrically impossible dimensional combinations, e.g., those with overlapping or very close barriers.

The iterative process did not give the chance to see the results obtained for every variant, but the outcomes for all the topologies studied were saved in .txt and .xls files for post processing intents. From these files, it is easily extractable any information concerning the performances of any alternative rotor variant, and the required comparisons can be accomplished. 


\subsection{Stator Design}

During the design of a SynRM, the stator and rotor are typically managed independently. A previously validated design algorithm for three-phase induction motors with a power between $0.5 \mathrm{~kW}$ and $100 \mathrm{~kW}$ was therefore used for the stator sizing [41]. This choice is justified by the fact that generally the stator of a SynRM is equivalent to that of an induction motor. Nevertheless, this is not enough to ensure correct sizing. Indeed, the stator structure geometry should be designed together with the rotor one, as they are interdependent. However, it is also essential to reduce the simulation time as much as possible though the minimization of the number of the design parameters that can be modified. Hence, during the study, the stator structure has been kept fixed and only rotor dimensions (in terms of shape and size of the flux barriers) have been varied. The outputs of the chosen design algorithm were then associated to the respective Flux 2D parameters to create the stator geometry.

In order to define the correct stator sizing, Mathcad was applied, permitting to find the preliminary stator sizes. Though, this was considered as a preparatory stage with respect to FEA. In Table 1 the stator design starting data are given and the results of the main sizing calculations of to the stator geometry are shown in Table 2 and Figure 2. In the preliminary design, it was chosen to prefer a traditional three-phase ISDW with a single layer. The power factor value of 0.8 shown in Table 1 derives from a previous choice concerning the design of the stator only. Clearly, the overall value for the SynRM could be lower, and it will be accurately calculated by means of FEA.

Table 1. Starting data for the stator design.

\begin{tabular}{cccc}
\hline Parameter & Symbol & Value & Unit \\
\hline Rated power & $P_{N}$ & 5500 & $\mathrm{~W}$ \\
Number of pole pairs & $p$ & 2 & - \\
Line voltage & $U_{1}$ & 400 & $\mathrm{~V}$ \\
Phase voltage & $U_{1 f}$ & 230.94 & $\mathrm{~V}$ \\
Supply frequency & $f$ & 50 & $\mathrm{~Hz}$ \\
Connection type & - & $\mathrm{Y}$ & - \\
Rated power factor & $\cos \varphi$ & 0.8 & - \\
Rated efficiency & $\eta$ & 0.85 & - \\
Rated speed & $n_{\mathrm{N}}$ & 1500 & $\mathrm{r} / \mathrm{min}$ \\
Slot number & $Z$ & 36 & - \\
\hline
\end{tabular}

Table 2. Output data of the stator design.

\begin{tabular}{cccc}
\hline Parameter & Symbol & Value & Unit \\
\hline Rated phase current & $I_{1 f}$ & 11.674 & $\mathrm{~A}$ \\
Outer stator diameter & $D_{1 e}$ & 0.192 & $\mathrm{~m}$ \\
Inner stator diameter & $D_{\text {int }}$ & 0.120 & $\mathrm{~m}$ \\
Air gap & $\delta$ & 0.385 & $\mathrm{~mm}$ \\
Active part length & $L_{1}$ & 0.151 & $\mathrm{~m}$ \\
Turns per slot & $n_{c}$ & 23 & - \\
Fill factor & $k_{u}$ & 0.4 & $\mathrm{~mm}$ \\
Slot dimension & $a_{s}$ & 2 & $\mathrm{~mm}$ \\
Slot dimension & $h_{01}$ & 1 & $\mathrm{~mm}$ \\
Slot dimension & $h_{s}$ & 2 & $\mathrm{~mm}$ \\
Slot dimension & $b_{z 1}$ & 5.454 & $\mathrm{~mm}$ \\
Slot dimension & $b_{1}$ & 5.541 & $\mathrm{~mm}$ \\
Slot dimension & $b_{2}$ & 8.587 & $\mathrm{~mm}$ \\
Slot dimension & $h_{j 1}$ & 15.593 &
\end{tabular}




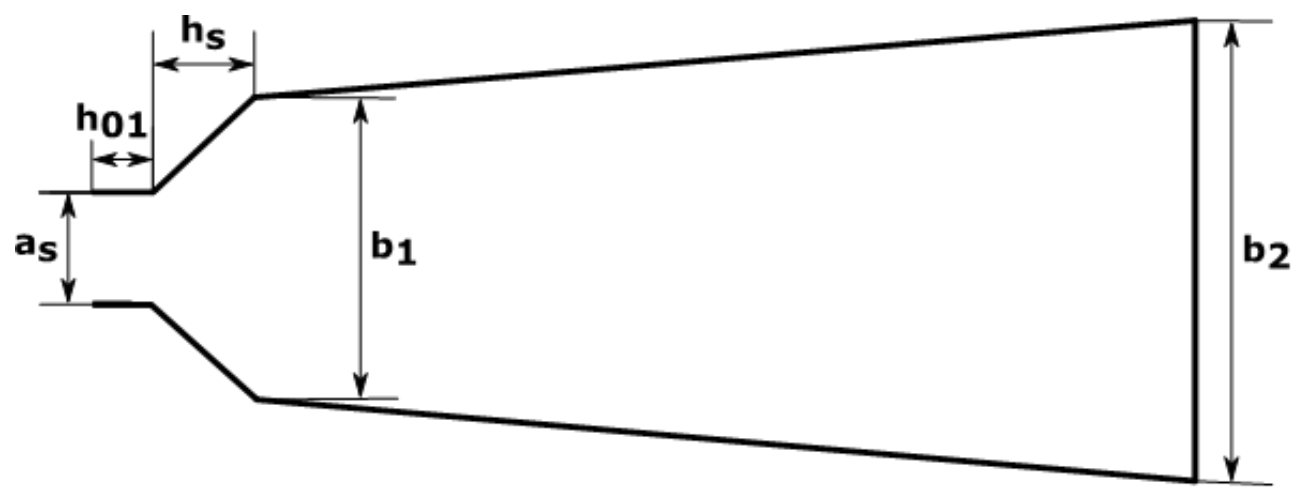

Figure 2. Main stator slot dimensions.

In FEA, it is necessary to define a mesh over the studied machine structure: it is a set of basic polygons, e.g., triangles, whose vertices (known as nodes) are the points considered to perform the calculations. The number of elements that make up the mesh determines the resolution - the greater the number, the greater the precision of the results. On the other hand, however, the more nodes there are, the more time will be devoted to the simulation. It is therefore necessary to reach a compromise.

It is important to have a denser mesh in the stator teeth, where saturation can be occurred due to the high flux. Another area that requires a denser mesh is the air gap, as most of the magnetic energy is stored there. It is good to divide it into two or three parts, to have greater precision in calculating the torque [42]. We decided to divide it in two parts: "air gap rotor" and "air gap stator". In fact, to achieve the stability of the simulation, it is necessary to decouple the stator union, to which all the static parts belong, and the rotor union, which includes the rotating parts (Figure 3).

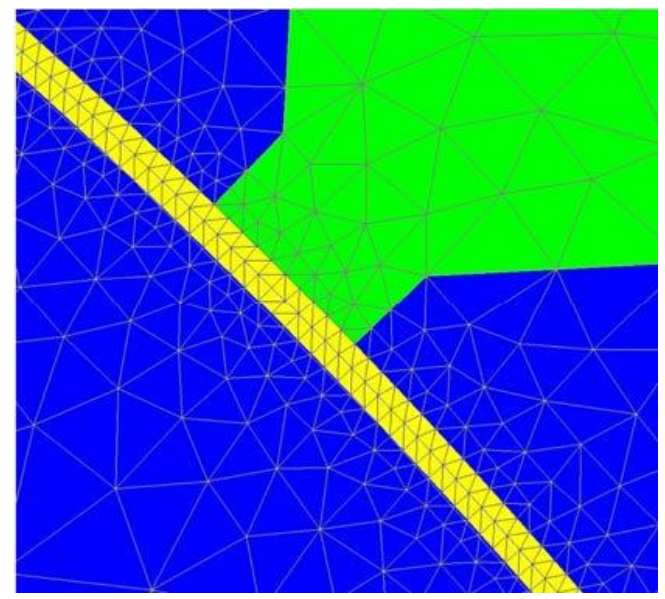

Figure 3. Mesh in the air gap and in regions close to it.

\subsection{Pre-Processing of the Rotor Geometry}

The first step to take in the rotor design is to determine the flux barriers number by considering the issues stated in Section 1 and in particular in $[9,14]$, it was decided to use 3 barriers, that have been appropriately distributed within the structure of the rotor. Their shape must follow stator flux lines path as much as possible (Figure 1) otherwise, their thickness can be adjusted to determine the rotor best configuration. Flux barrier edges were determined by following the flux lines defined by (2) and (3). Regrettably, these ideal nonlinear flux barrier shapes cannot be accurately drawn in Flux 2D, as Python only allows for the drawing of simple graphical primitives, such as points, segments and arcs. 
Thus, the shapes had to be approximated by lines. A very significant problem related to this is to find the compromise between the large number of lines necessary for the precise approximation of the actual shape, and the duration of the simulation.

The practical procedure implemented in Flux 2D to draw these flux barriers is based on making it to communicate with MATLAB, and on the concept of parametrization. The aim is to find the optimal geometry by changing the position, thickness, and shape of these barriers.

This is performed in the first place by defining the appropriate number of points, which will be connected by lines to draw the flux barriers. Two parameters were associated with each point, corresponding to the abscissa and the ordinate, respectively. To shorten the simulation times, in this phase of the study, the rounded ends of the barriers are represented by two straight lines, and the edges of the stator slots are rectangular.

Subsequently, a strategy was established in order to define the coordinates of 3 starting points of the barriers, necessary to determine the $C$ constants of the 3 central lines of the barriers. A particular algorithm was developed to draw the lower, middle and upper lines of each barrier. Figure 4 shows the 3 lines that define the first barrier, and the points to be parameterized for the lower line. This must be done for each line, so the points must be connected by segments to close the shape of the barriers. Each line can be moved by means of changing the parameters, resulting in various widths of the barriers.

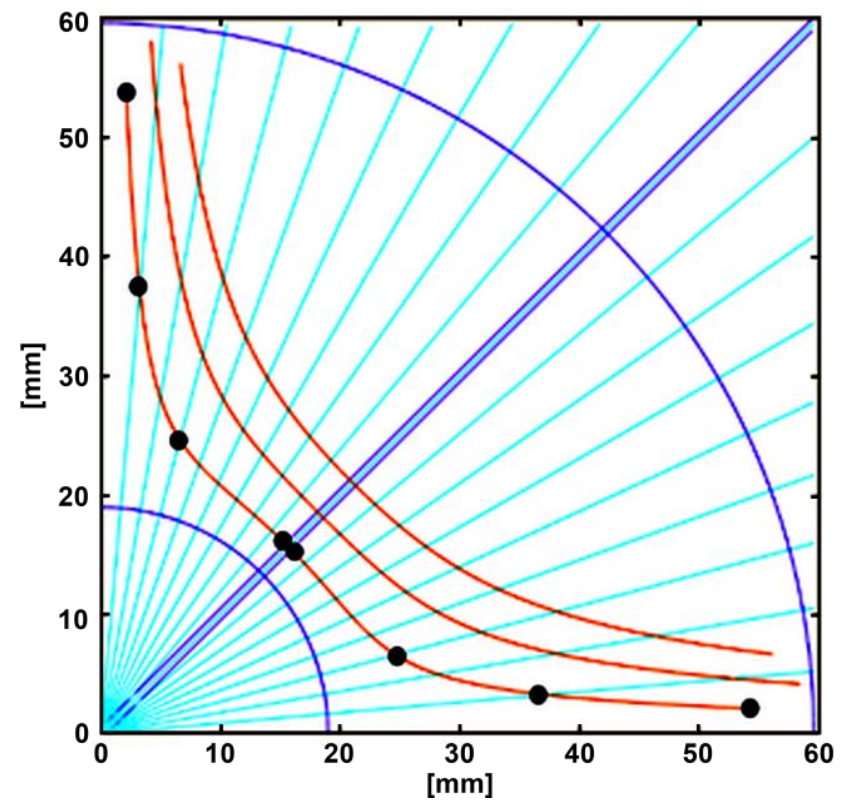

Figure 4. The 3 lines of the first barrier are in red, and the points were chosen to be parameterized for the lower line.

Some authors proposed to avoid the ribs at the center of each barrier, especially when the maximum speed is not very high (see Section 1); in fact, in these cases, in addition to not exploiting their mechanical function, they can also negatively influence the magnetic behavior of the machine, because these ribs represent possible paths in which the flux can flow, reducing the saliency ratio and, as a consequence, the performance of the machine. Nevertheless, in this study it was decided to introduce them, to develop a design procedure that could be feasible even for higher machine speeds to guarantee greater mechanical resistance.

The thickness of the ribs was set at $1 \mathrm{~mm}$. In Figure 5, all the lines that define the 3 barriers and the points that define the ends of the ribs are shown. 


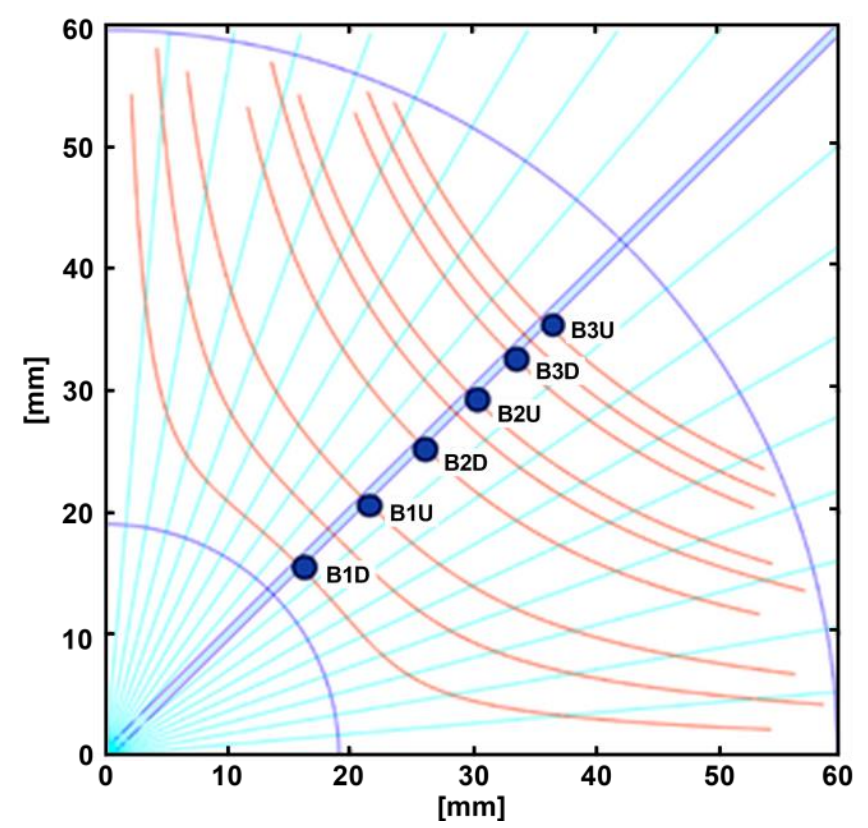

Figure 5. Lines defining the 3 barriers (red) and the end points (blue) of the ribs, initially set at $1 \mathrm{~mm}$ width.

After defining a satisfactory number of points to be parameterized for each barrier, an iterative MATLAB code was implemented, which made possible to construct a matrix containing all the values that the geometric parameters can assume. A matrix consisting of 4500 lines was obtained, and consequently the same number of configuration variants. Hence, it was necessary to restrict the number of possible geometries.

In fact, this procedure needed the imposition of certain geometrical and mechanical constraints, as some of the obtained configurations were not physically achievable. For example, it is evident that the displacement of lines belonging to different barriers could unavoidably lead to an overlap of the barriers. For example, it could happen that the upper point of the first barrier (B1U) to move away from the center with respect to the lower point of the medium one (B2D). Furthermore, a constraint has been introduced on a macroscopic geometric parameter of the SynRM, i.e., the insulation ratio (the ratio between the quantity of air and that of iron) along the $q$-axis [43]. These aims were achieved by imposing geometrical limitations on the parametrized points that define the ends of the ribs.

By eliminating the impractical and unsuitable geometric variants, the number of appropriate alternatives has been reduced to 154 . Further, the aim was to find among these acceptable geometries the one that achieves the best performance in terms of average torque, torque ripple, efficiency, and power factor.

\section{Results}

After having thoroughly studied the remaining 154 configurations using FEA, some deliberations were drawn. The values of the mean torque, torque ripple, efficiency and power factor of each configuration were plotted in graphs (Figures 6-9). Here it can be noted that each graph is divided into five parts: each zone corresponds to a position of the lowest line of the barrier closest to the shaft. The first zone corresponds to the lowest line in the most distant position from the shaft. 


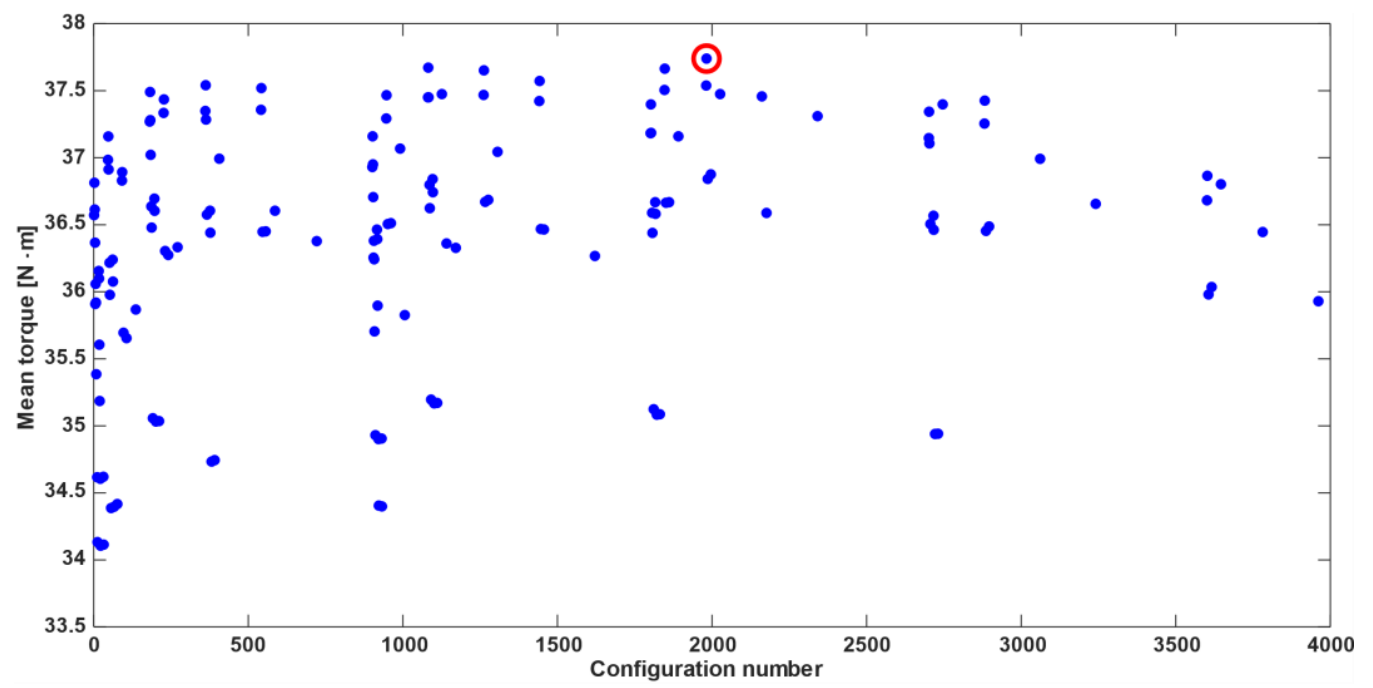

Figure 6. Values of mean torque for the 154 selected configurations (the maximum value, $37.74 \mathrm{~N} \cdot \mathrm{m}$, is circled in red).

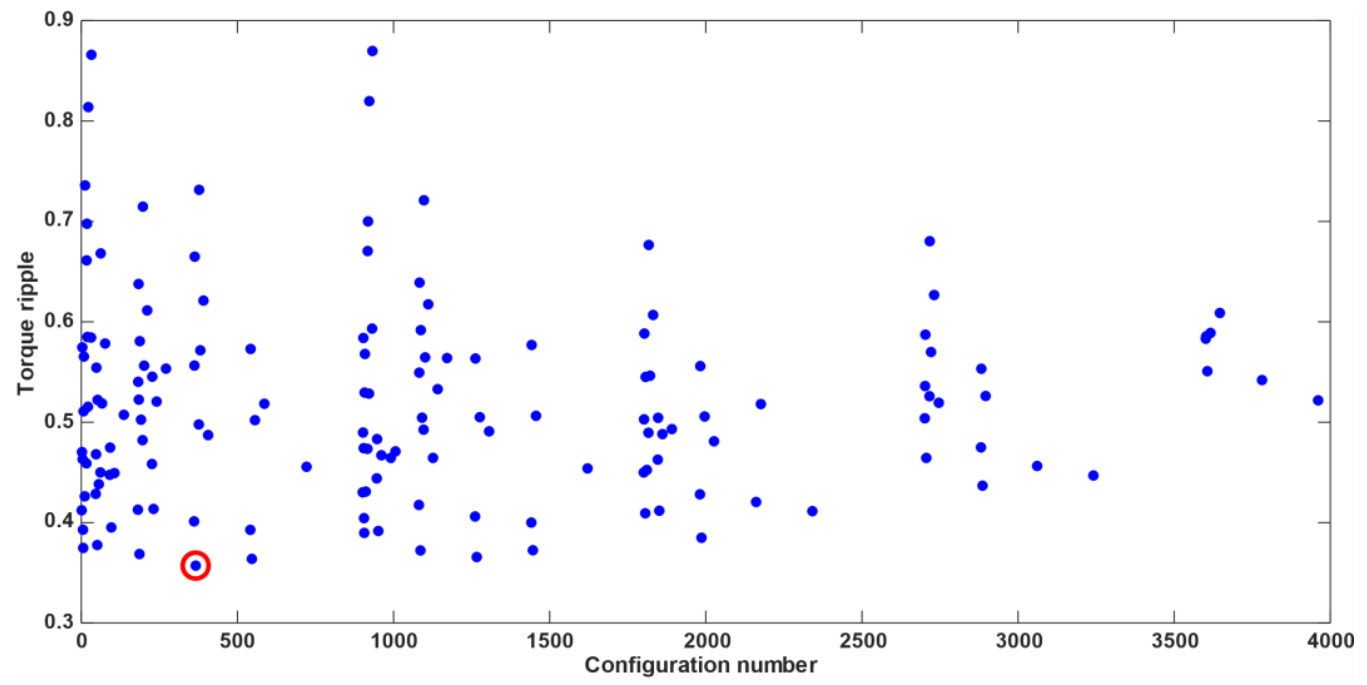

Figure 7. Values of torque ripple for the 154 selected configurations (the minimum value is circled in red).

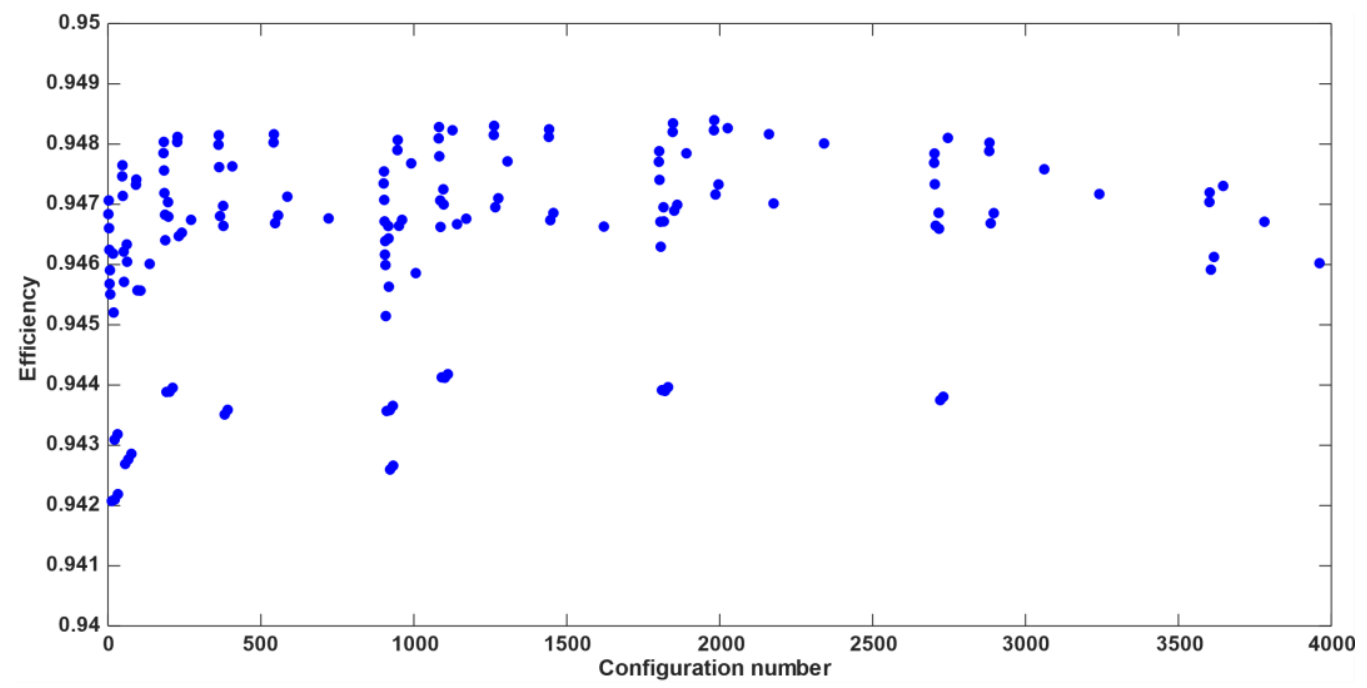

Figure 8. Values of efficiency for the 154 selected configurations. 


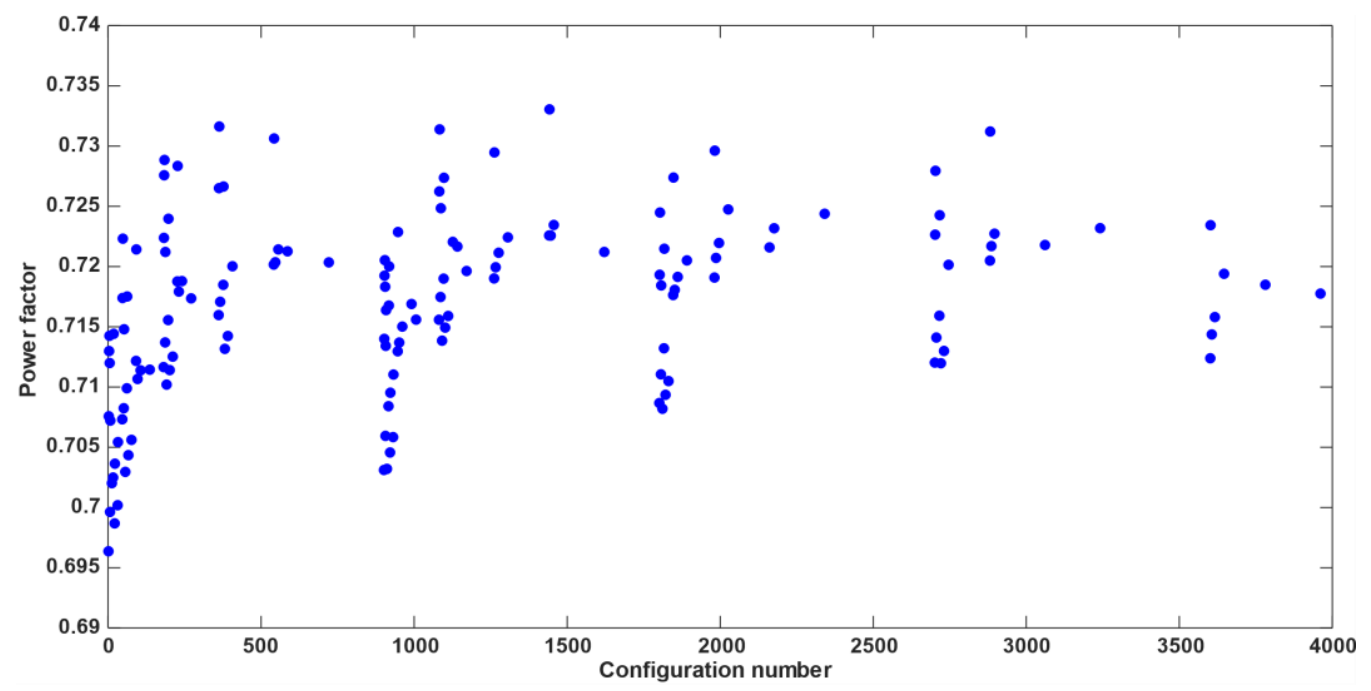

Figure 9. Values of power factor for the 154 selected configurations.

Regarding the mean torque, it results in a range between $34 \mathrm{~N} \cdot \mathrm{m}$ and $38 \mathrm{~N} \cdot \mathrm{m}$ (Figure 6). The highest value is produced by configuration number 1982, circled in red, which can deliver $37.74 \mathrm{~N} \cdot \mathrm{m}$. This is not necessarily the best configuration from all points of view. For this reason, the torque ripple and other parameters have been considered. Note that the number which identifies each configuration remains between 1 and 4500, even if only 154 configurations were selected among the initial 4500 topologies.

Torque ripple is calculated as $T_{\text {ripple }}=\left(T_{\text {max }}-T_{\text {min }}\right) /\left(T_{\text {mean }}\right)$ and reaches its minimum value, equal to 0.357 , in the first zone, where the lowest line is at the furthest position from the shaft; thus, geometry with a wider central path for the flux reduces the torque ripple (Figure 7). This value of torque ripple can be considered high, but-as already mentionedin this study the stator geometry remains unchanged during rotor optimization. In order to lower the torque ripple, the stator slot opening should be optimized.

As can been seen in Figure 8, the efficiency is not greatly influenced by the different configurations; in fact, in almost all cases it reaches values higher than 0.94 . This is due to the fact that Joule losses continue to be constant, while iron losses undergo an increase when, in some part of the rotor, flux density reaches values close to saturation. However, their influence on the efficiency is small in percentage.

The power factor values range from 0.695 to 0.735 , lower than that of anduction machine of a similar power (Figure 9).

It is interesting to notice how the insulation ratio affects the power factor and the torque ripple: by increasing the percentage of air with respect to that of iron, the power factor generally has an increasing trend, since there is a decrease of $L_{q}$. The problem is that, as the insulation ratio grows, the torque ripple also increases, because of the greater amount of air that is defined when the outermost line is closer to the outer edge of the rotor.

\subsection{Selection of the Best Rotor Geometry}

Based on the above considerations, the average torque and torque ripple values of the best configurations resulting from the selection are shown in Figure 10. The average torque values of the best configurations are represented in red, while their torque ripple in black.

While other configurations allow for higher average torque values, they also achieve higher torque ripple. Therefore, configuration number 366 is selected as the best one: its average torque is $T_{\text {mean }}=36.58 \mathrm{~N} \cdot \mathrm{m}$ with a ripple $T_{\text {ripple }}=0.358=35.8 \%$ (these values are circled in Figure 10). 


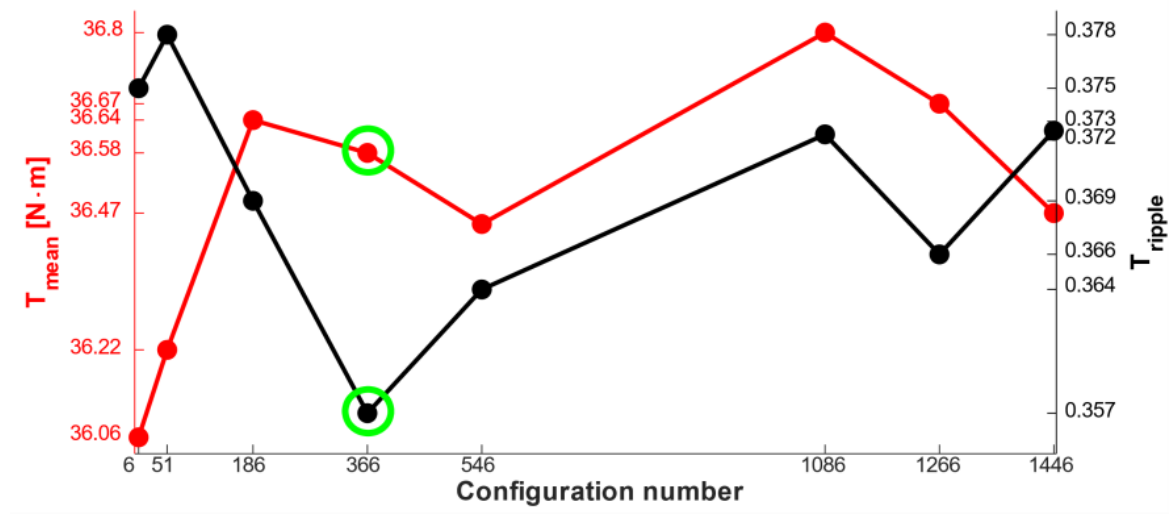

Figure 10. $T_{\text {mean }}$ (red) and $T_{\text {ripple }}$ (black) of the best configurations. The solution chosen as the best one (number 366) is circled by green.

In a subsequent phase of the study, the lines of each barrier were varied by $0.5 \mathrm{~mm}$ back and forth, in order to find a better geometry, which guarantees an average torque greater than $36 \mathrm{~N} \cdot \mathrm{m}$ with a low torque ripple. At this stage, the final lines of the barriers are still drawn by only two straight lines. This step was necessary, as the barriers were initially moved by a step of $\pm 2 \mathrm{~mm}$ to keep simulation times relatively low.

Once this new optimization has been completed, configuration number 366, shown in Figure 11, is still the best.
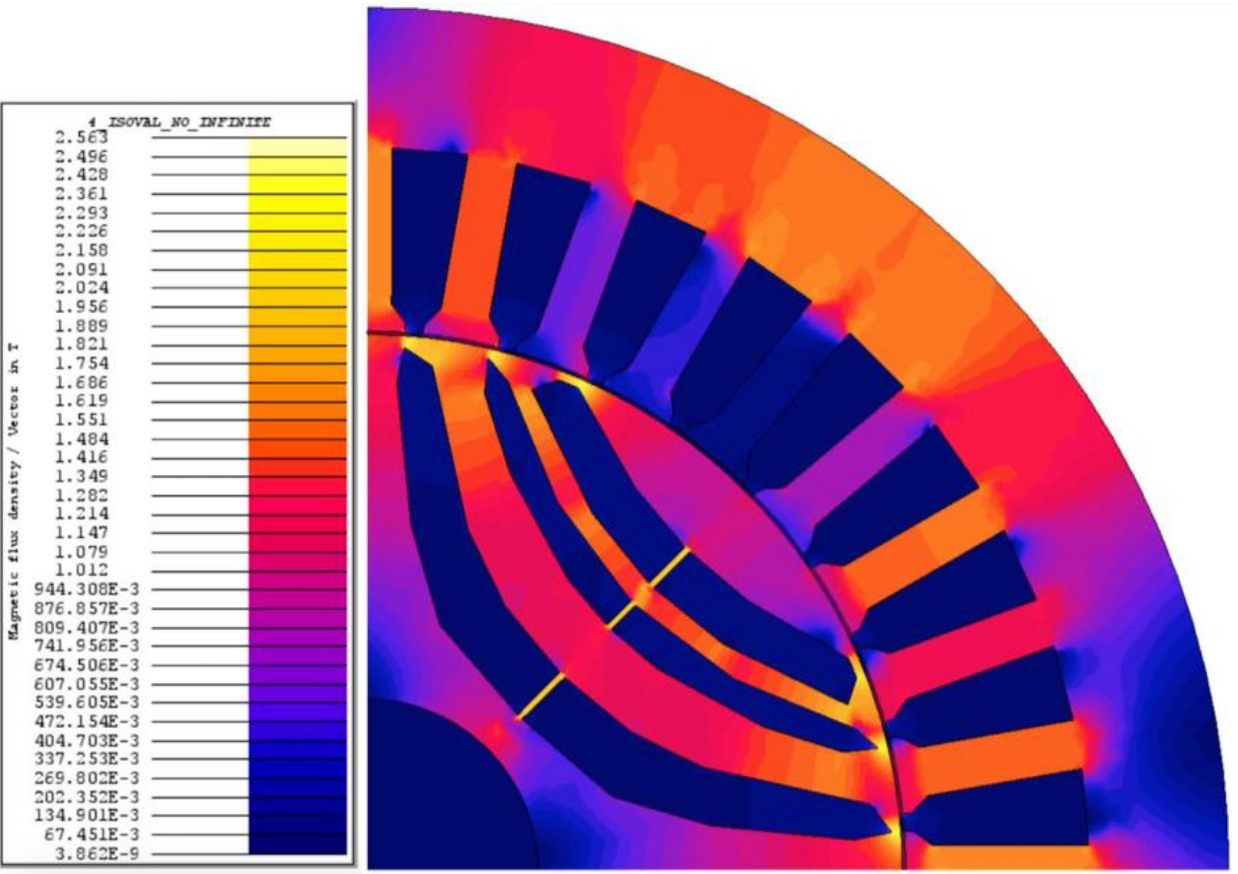

Figure 11. Flux density distribution color map of the best configuration chosen (with sharp-edged barriers). The numerical values written on the right correspond to the colors which represent the magnetic flux density in the different zones of the machines and are expressed in Tesla $(\mathrm{T})$.

Figure 11 shows the color map of the flux density in this variant. As it can be seen, the central barrier has a reduced thickness with the aim to better facilitate the passage of the stator flux. The barrier closest to the shaft is thicker than the central barrier because it must follow the natural contour of the stator flux inside the rotor. Its lowest line is at the farthest point allowed from the shaft.

It is important to observe that the thickness of the layer between the two upper barriers is very thin, and this is the reason why the flux could be concentrated more in it, leading to 
saturation zones and therefore to greater iron losses in the rotor. As shown in Figure 11, in this area the flux density reaches values between $1.5 \mathrm{~T}$ and $1.8 \mathrm{~T}$, which correspond to working points on the knee of the $B-H$ curve. Higher flux density values can be found in the ribs and bridges $(2.3 \div 2.4 \mathrm{~T})$, as expected, as the flux is more concentrated in thinner areas. This is partly due to the still sharp ends of the barriers. When rounding them, the flux density values will slightly decrease.

As already mentioned, in order to reduce the calculation times, the ends of the barriers were traced by using only two straight lines, and the stator slots were considered rectangular. In the final step, both were rounded. This is necessary for two main reasons: to avoid local saturations and to increase the mechanical rigidity against centrifugal forces.

In defining the final shape of the SynRM, the aspects related to the punching technology must also be considered (mainly technical limitations and costs).

The flux density color map of the of the final SynRM variant (with rounded shapes) is shown in Figure 12. Since a single simulation had to be performed and the computation time was not crucial, the round shapes of both stator and rotor were drawn using many more points and interconnecting lines, as in the previous case. It can be noticed that the flux density values are slightly lower than in the case where sharp-edged barriers were considered (as can be seen in Figure 11), highlighted by a more homogeneous distribution of the color map. For the average torque, $36.5 \mathrm{~N} \cdot \mathrm{m}$ was found, practically close to the previously obtained value. This is a confirmation of the fact that the results were not significantly affected considering simplified geometries, so the results of the less timeconsuming optimizations are entirely relevant.
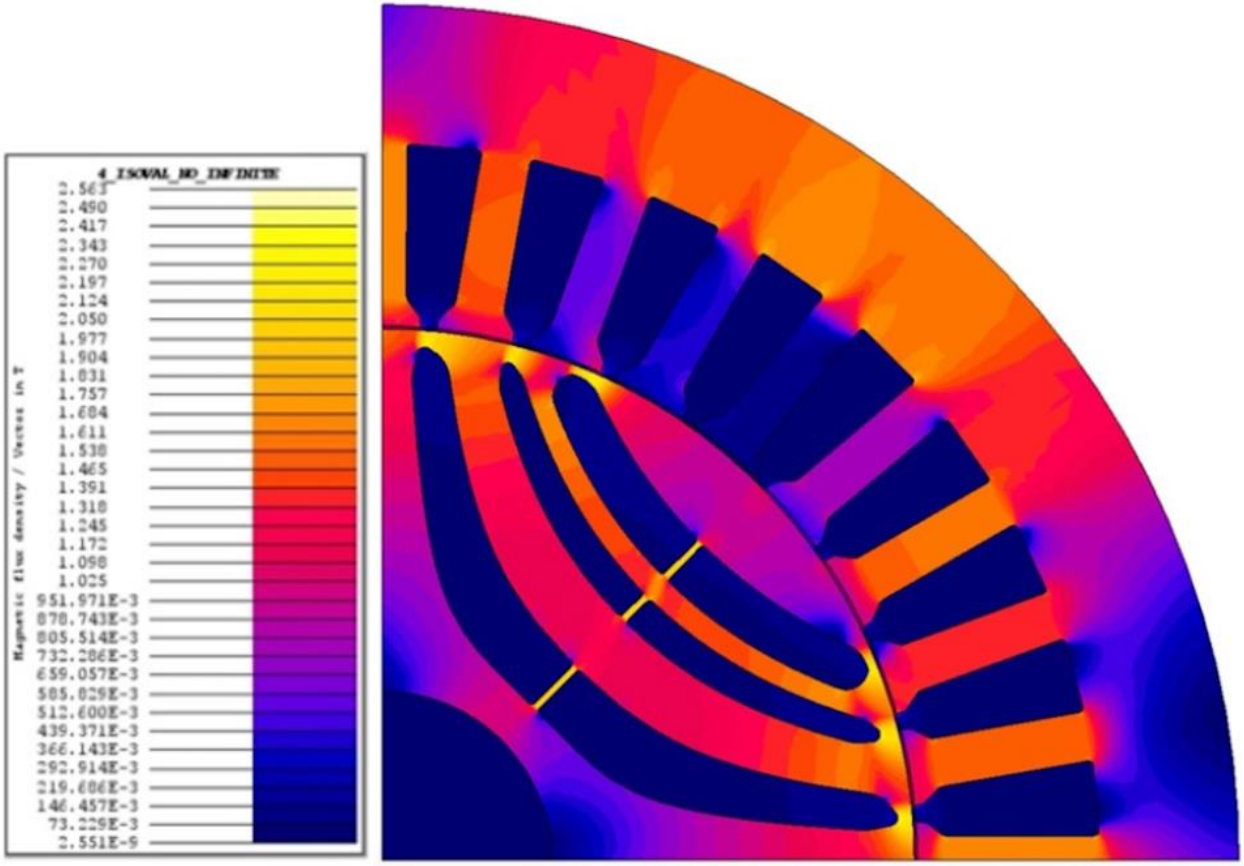

Figure 12. Flux density distribution color map of the best configuration chosen, in which the ends of the barriers have been rounded. The numerical values written on the right correspond to the colors which represent the magnetic flux density in the different zones of the machines and are expressed in Tesla (T).

For the sake of completeness, to see broadly how the motor designed could actually look, the three-dimensional drawing is created. To do this, the geometry was exported from Flux 2D in .dxf format. Then, this is imported into the ANSYS software to perform the extrusion by selecting the stator and rotor, as well as the stator windings. 
The software used automatically generates the end-windings by appropriately entering the slot dimensions and the coil pitch. The three-dimensional model from different angles is shown in Figure 13.

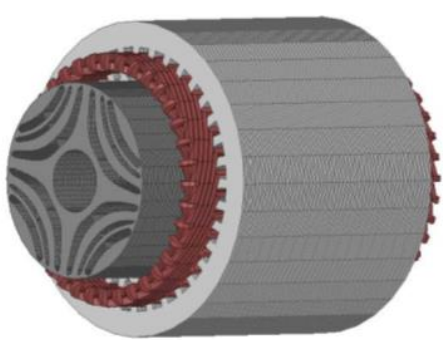

Figure 13. View of the SynRM 3D model from different angles.

The 3D electromagnetic analysis was not considered in this work.

\subsection{Current Angle}

In the simulations, the three phase currents $I_{A}, I_{B}, I_{C}$ defined in (5) are mutually displaced by $120^{\circ}$ in time and depend from a current angle $\gamma$, measured from $d$-axis:

$$
\left\{\begin{array}{c}
I_{A}=\sqrt{2} I \sin (2 \pi f t+\gamma) \\
I_{B}=\sqrt{2} I \sin \left(2 \pi f t-\frac{2}{3} \pi+\gamma\right) \\
I_{C}=\sqrt{2} I \sin \left(2 \pi f t-\frac{4}{3} \pi+\gamma\right)
\end{array}\right.
$$

In these equations, $t$ is the time and $f$ is the supply frequency, as defined in Table 1. When the $d$-axis is aligned with the axis of the stator phase $A, \gamma$ is usually chosen equal to $45^{\circ}$, if the saturation is not considered. Otherwise, this angle depends on the value of the stator current, and it can be greater than $45^{\circ}$, but still close to it [44]. In this work, in order to simplify the Flux 2D model, $d$-axis is aligned with the axis between the stator phases $B$ and $A$. The angle between direct axis and phase $A$ is therefore $15^{\circ}$. For this reason, a current angle lower than $45^{\circ}$ is expected; it is selected properly to develop the maximum torque and it results equal to $34^{\circ}$.

In this subsection, the best geometry is used to graphically verify the correctness of the imposed current angle equal to $34^{\circ}$ at the beginning of the optimization procedure. The torque is influenced by the reciprocal position of rotor and stator windings. An iterative procedure to vary the angle is therefore necessary, in order to find the one that allows a MTPA operation. A graph is realized showing the relation of the current angle with torque, power factor and efficiency (Figure 14).

The mean value of the torque assumes a wide range of values by varying the angle from $0^{\circ}$ to $55^{\circ}$; its maximum value is at a current angle of $34^{\circ}$. It can be seen how the variation of the current angle has a great influence on power factor value too. In this case, it reaches the maximum value of 0.76 at $40^{\circ}$, while at $34^{\circ}$ it is equal to 0.725 . The efficiency, represented by the yellow line in Figure 14, varies from around 0.91 to 0.95 . Finally, it can be seen that the maximum torque and the maximum power factor are not reached at the same current angle; since a certain angle has to be chosen, a compromise is necessary. The achievement of the maximum possible torque was decided, as indicated in Figure 14. 


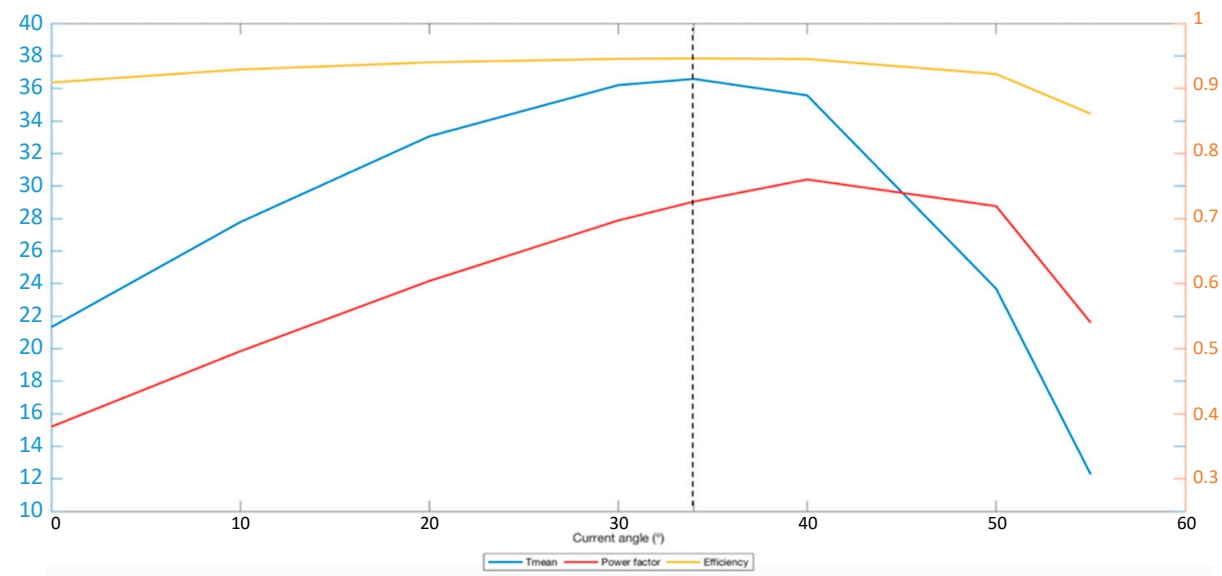

Figure 14. Current angle influence on average torque (expressed in $\mathrm{N} \cdot \mathrm{m}$ ), power factor and efficiency.

\subsection{Ribs}

The effect of the thickness of the radial ribs that radially connect the flux barriers has been also evaluated. In the literature, it is stated that this thickness can be even less than $1 \mathrm{~mm}$ for low power machines [45]. On the other hand, for high-speed machines, these ribs are essential to sustain rotor integrity against mechanical forces to which it is subjected and the increase in temperature. In case of large machines, ribs can have a greater thickness without causing excessive decreases in performance; on the contrary, radial and tangential ribs in low-speed machines, such as the one considered here, have a more significant impact [19,32]. Since the mechanical analysis was not in the scope of this research, this thickness has been set equal to $1 \mathrm{~mm}$ during the rotor optimization.

Once the best rotor configuration defined, different thicknesses have been evaluated (as $1 \mathrm{~mm}, 1.5 \mathrm{~mm}, 2 \mathrm{~mm}$, and $2.5 \mathrm{~mm}$ ), and a geometry without any ribs, too. In Figure 15 the color maps of the magnetic flux density obtained by means of simulation for the two extreme cases are shown: absence of ribs Figure 15a and thickness equal to $2.5 \mathrm{~mm}$ Figure 15b.

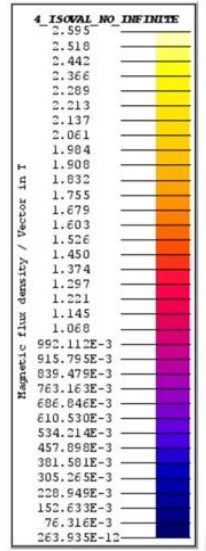

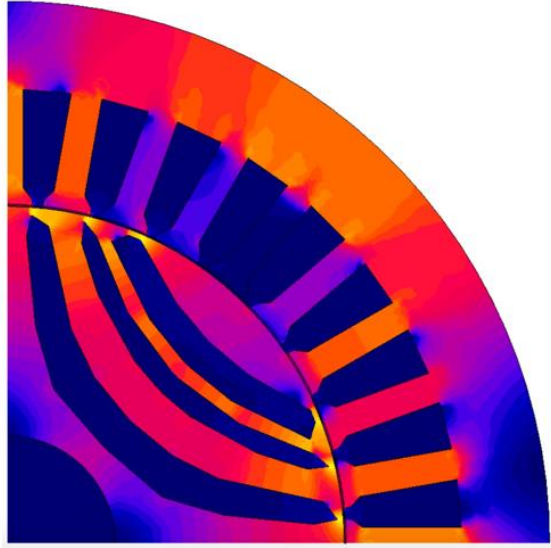

(a)

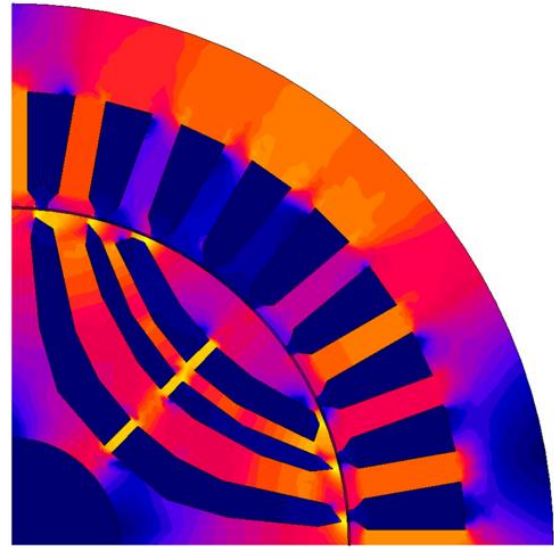

(b)

Figure 15. Color maps of the magnetic flux density obtained by means of simulation for the two extreme cases: (a) absence of ribs; (b) rib thickness equal to $2.5 \mathrm{~mm}$.

It should be also of interest to see how the mean value of the torque varies with the thickness of the ribs (Figure 16). As expected, the torque diminishes as this thickness increases, since the reluctance value along the $q$-axis decreases. Thinner barriers, with the same currents in the stator windings, tend to saturate first, if compared to thicker barriers, which instead become a passage for the flux along $q$-axis, increasing $L_{q}$ and reducing the general performance of the machine. Passing from a geometry without ribs to one with 
$2.5 \mathrm{~mm}$ width, the torque decreases by more than $3 \mathrm{~N} \cdot \mathrm{m}$, from $37.4 \mathrm{~N} \cdot \mathrm{m}$ to $35.2 \mathrm{~N} \cdot \mathrm{m}$. Thus, the $1 \mathrm{~mm}$ ribs applied in the initial design can be considered a good compromise between the electromagnetic behavior and the mechanical strength of the rotor.

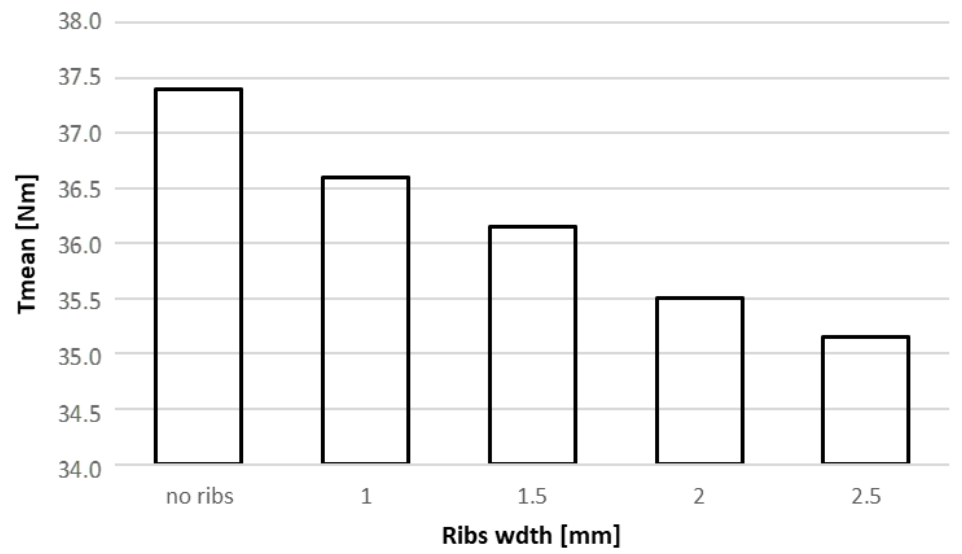

Figure 16. Rib width influence on the mean torque.

It was also of interest to study the change of power factor due to growing the rib width (Figure 17). As it can be seen, the power factor also reduces when ribs thickness enlarges. It has the maximum value of 0.736 in absence of ribs, because it is dependent on the structure saliency. In this case, $L_{q}$ can have lower values, and there are fewer points on the rotor surface in which the material saturates.

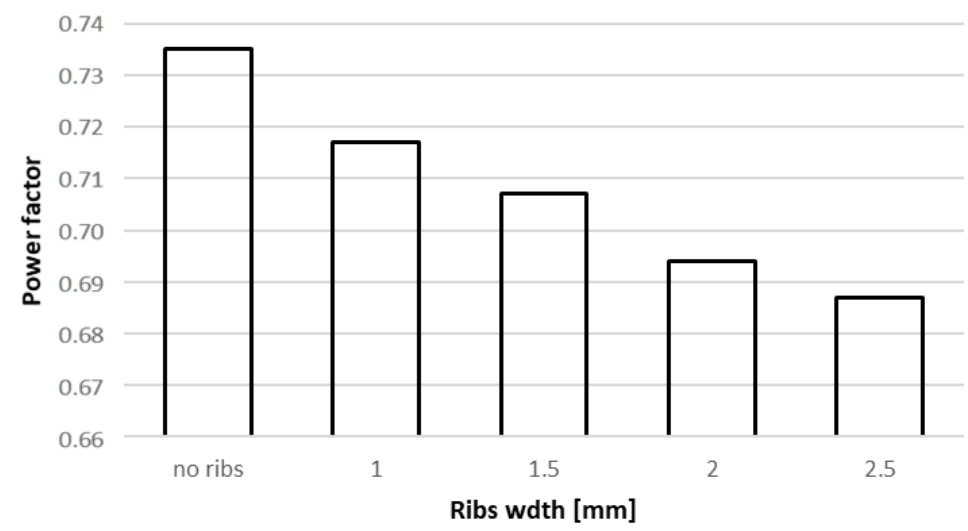

Figure 17. Rib width influence on power factor.

When analyzing the effect of the rib width on the efficiency and the torque ripple, it was observed that this parameter does not have a significant effect on them: the obtained values were between 0.9475 and 0.9445 for the efficiency, and between 0.361 and 0.3653 for the torque ripple. All these considerations again emphasize the correct selection of the rib width performed during the design of the electrical machine.

\subsection{Double-Layer Winding}

Usually, for low-power machines a single layer of conductors in the stator slots is preferred, and there is only one phase in each slot; this is in fact simpler from a technological point of view. However, it is interesting to see how the performance of the machine is influenced by employing a double-layer. In particular, this allows the consideration of a short-pitched winding case, otherwise not possible in a single-layer configuration. It means that conductors of different phases share the same slot. This undoubtedly implies a greater complexity in arranging the windings and a higher risk of winding faults. In this work, only the performance of the machine is analyzed, without economic considerations. In fact, pitch shortening is often useful to eliminate certain harmonics. 
To shorten the pitch from 9 (full pitch) to 8 (short pitch) was chosen. The windings are arranged as shown in Figure 18; in each slot there are conductors belonging to two different phases.

$\tau_{P}$

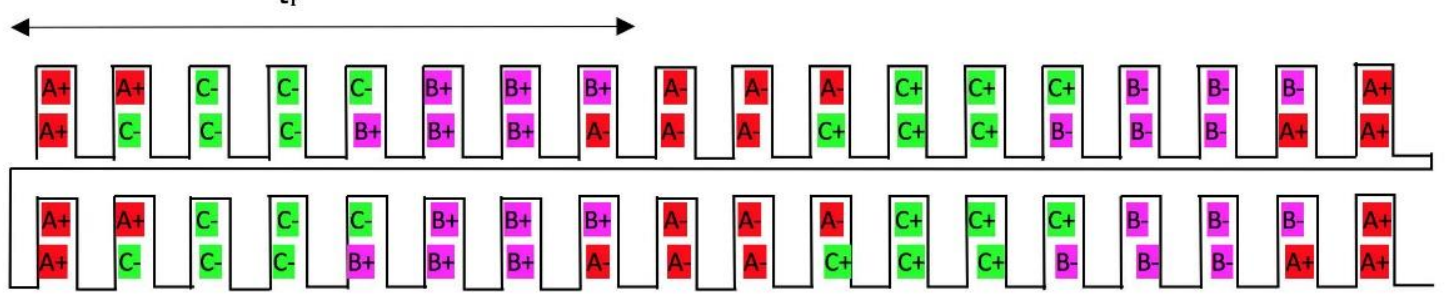

Figure 18. Double-layer winding configuration with short pitch equal to 8 .

To obtain the new parameters of the stator geometry, the sizing procedure previously performed on Mathcad has been used again. Since the number of conductors in a doublelayer winding must be even, 24 turns per slot have been chosen instead of 23 (parameter $n_{c}$ in Table 2). As a consequence, the dimensions of the slots also changed, but in a very small amount, if compared to the single-layer. In fact, only the last two parameters of Table 2 have been modified: $b_{2}=8.638 \mathrm{~mm}$ and $h_{j 1}=15.304 \mathrm{~mm}$.

As it can be seen in Table 3 , there is a general improvement in performance when short pitch windings are applied; the mean torque increases by about $1 \mathrm{~N} \cdot \mathrm{m}$, and there is a reduction in torque ripple, while the power factor is also improved.

Table 3. Performance comparison between single-layer full pitch and double-layer short pitch winding, for the best rotor configuration.

\begin{tabular}{ccccc}
\hline & $\boldsymbol{T}_{\text {mean }}[\mathbf{N} \cdot \mathbf{m}]$ & Torque Ripple & Efficiency & Power Factor \\
\hline Full pitch & 36.58 & 0.358 & 0.9461 & 0.7171 \\
Short pitch & 37.52 & 0.330 & 0.9457 & 0.7209 \\
\hline
\end{tabular}

\section{Discussion}

A new software-based technique for designing an optimized configuration of a SynRM has been developed and presented in this paper. The procedure begins with the definition of a MATLAB code to design and vary the position of suitably shaped rotor flux barriers. By means of the coupling between MATLAB and Flux 2D, this method modifies and analyzes different geometries in which the flux barriers are consisting of segments. To find the best rotor configuration, the mean torque, torque ripple, efficiency and power factor were evaluated in a post-processing stage.

A first interesting outcome regards the torque ripple, which decreases for configurations where the lowest barrier is further away from the shaft; in this way, a wider central path is offered to the magnetic flux. Conversely, if the outermost line is nearer to the outer edge of the rotor, the torque ripple increases. The efficiency, on the other hand, is not very influenced by the chosen configuration-it almost always achieves values a little bit higher than 0.94 . The power factor is between 0.695 and 0.735 . If the insulation ratio is augmented, and therefore the percentage of air with respect to that of iron is increased, the power factor usually has an increasing trend, meanwhile the $L_{q}$ inductance decreases.

Since all simulation programs have been written with the parametrization approach, these can be easily modified to obtain the SynRMs most suitable for different speeds and geometrical constraints.

In the last part of this research, the optimization process has been extended by evaluating the effect of changing other parameters of the machine, i.e., the current angle, the thickness of the radial ribs, and the stator winding, with the aim to enhance the performance of the machine. 
Furthermore, the addition of ferrite magnets in the flux barriers could be considered to improve the power factor, though the particular shape of these barriers does not allow the standardization of the size of the magnets.

\section{Conclusions}

The aim of this work is to develop a general procedure to study the characteristics of mean torque, torque ripple and power factor of a generic SynRM. Thanks to the parametrization principle, a preliminary specific size of the machine is designed. By means of the communication between different software tools, some variations in its rotor geometry are executed, such as changing the number, the position and the thickness of the flux barriers. The optimization procedure leads to identifying the best rotor geometry among thousands possible configurations. The usefulness of this procedure is also given by its replicability for various sizes of machines, with different stator and rotor geometries, and its ability to reach an imposed performance target respecting the geometric and mechanical constraints that are necessary from time to time.

Author Contributions: Conceptualization, L.S.; methodology, L.S. and F.U.; software, F.U.; validation, F.U. and L.S.; formal analysis, F.U.; investigation, F.U.; resources, L.S.; data curation, F.U. and L.S.; writing - original draft preparation, L.F. and F.U.; writing—review and editing, L.F., F.U. and L.S.; supervision, L.S. All authors have read and agreed to the published version of the manuscript.

Funding: This research received no external funding.

Institutional Review Board Statement: Not applicable.

Informed Consent Statement: Not applicable.

Data Availability Statement: Data sharing not applicable.

Acknowledgments: The authors gratefully acknowledge the contributions of Mircea Ruba and Florin Pop Pigleșan from Technical University of Cluj-Napoca, Romania, for their collaboration to this research.

Conflicts of Interest: The authors declare no conflict of interest.

\section{References}

1. Ghahfarokhi, P.S.; Kallaste, A.; Vaimann, T.; Belahcen, A. Thermal analysis of totally enclosed fan cooled synchronous reluctance motor-state of art. In Proceedings of the IECON 2019-45th Annual Conference of the IEEE Industrial Electronics Society, Lisbon, Portugal, 14-17 October 2019; pp. 4372-4377.

2. Rezk, H.; Tawfiq, K.B.; Sergeant, P.; Ibrahim, M.N. Optimal Rotor Design of Synchronous Reluctance Machines Considering the Effect of Current Angle. Mathematics 2021, 9, 344. [CrossRef]

3. Kostko, J.K. Polyphase reaction synchronous motors. J. Am. Inst. Electr. Eng. 1923, 42, 1162-1168. [CrossRef]

4. Lipo, T.A. Synchronous reluctance machines-A viable alternative for AC drives? Electr. Mach. Power Syst. 1991, $19,659-671$. [CrossRef]

5. Staton, D.A.; Miller, T.J.E.; Wood, S.E. Maximising the saliency ratio of the synchronous reluctance motor. IEE Proc. B Electr. Power Appl. 1993, 140, 249-259. [CrossRef]

6. Vagati, A. Synchronous Reluctance Electrical Motor Having a Low Torque-Ripple Design. U.S. Patent No. 5,818,140, 6 October 1998.

7. Vagati, A.; Pastorelli, M.; Francheschini, G.; Petrache, S.C. Design of low-torque-ripple synchronous reluctance motors. IEEE Trans. Ind. Appl. 1998, 34, 758-765. [CrossRef]

8. Pellegrino, G.; Jahns, T.M.; Bianchi, N.; Soong, W.L.; Cupertino, F. The Rediscovery of Synchronous Reluctance and Ferrite Permanent Magnet Motors, Tutorial Course Notes; Springer briefs in electrical and computer engineering; Springer: Berlin/Heidelberg, Germany, 2016; pp. 109-114.

9. Kuci, E.; Henrotte, F.; Geuzaine, C.; Dehez, B.; De Gréef, C.; Versèle, C.; Friebel, C. Design optimization of synchronous reluctance machines for railway traction application including assembly process constraints. In Proceedings of the 2020 ICEM, Gothenburg, Sweden, 23-26 August 2020. [CrossRef]

10. Ban, B.; Stipetic, S. Design and optimization of synchronous reluctance machine for actuation of electric multi-purpose vehicle power take-off. In Proceedings of the 2020 ICEM, Gothenburg, Sweden, 23-26 August 2020.

11. Ban, B.; Stipetic, S.; Jercic, T. Minimum Set of Rotor Parameters for Synchronous Reluctance Machine and Improved Optimization Convergence via Forced Rotor Barrier Feasibility. Energies 2021, 14, 2744. [CrossRef] 
12. Credo, A.; Pescetto, P. Design optimization of a synchronous reluctance motor based on operating cycle. In Proceedings of the 2020 ICEM, Gothenburg, Sweden, 23-26 August 2020. [CrossRef]

13. Cupertino, F.; Pellegrino, G.; Gerada, C. Design of synchronous reluctance motors with multiobjective optimization algorithms. IEEE Trans. Ind. Appl. 2014, 50, 3617-3627. [CrossRef]

14. Pellegrino, G.; Cupertino, F.; Gerada, C. Automatic design of synchronous reluctance motors focusing on barrier shape optimization. IEEE Trans. Ind. Appl. 2015, 51, 1465-1474. [CrossRef]

15. Mohanarajah, T.; Nagrial, M.; Rizk, J.; Hellany, A. Design of high-efficiency synchronous reluctance machines. In Proceedings of the 2019 ICEERP, Sydney, Australia, 24-28 November 2019.

16. Nashiki, M.; Satake, A.; Kawai, Y.; Yokochi, T.; Okuma, S. A new flux-barrier-type reluctance motor with a slit rotor. IEEE Trans. Ind. Electron. 1999, 46, 1199-1206. [CrossRef]

17. Yilmaz, Y.B.; Bostanci, E. Effects of rotor flux barrier design on torque ripple and high speed performance of synchronous reluctance machines. In Proceedings of the 2020 ICEM, Gothenburg, Sweden, 23-26 August 2020.

18. Moghaddam, R.-R.; Magnussen, F.; Sadarangani, C. Novel rotor design optimization of synchronous reluctance machine for low torque ripple. In Proceedings of the 2012 ICEM, Marseille, France, 2-5 September 2012. [CrossRef]

19. Moghaddam, R.-R. Synchronous Reluctance Machine (SynRM) in Variable Speed Drives (VSD) Applications. Ph.D. Thesis, Royal Institute of Technology, Stockholm, Sweden, 2011; pp. 151-152.

20. Yammine, S.; Henaux, C.; Fadel, M.; Desharnais, S.; Calégari, L. Synchronous reluctance machine flux barrier design based on the flux line patterns in a solid rotor. In Proceedings of the ICEM 2014, Berlin, Germany, 2-5 September 2014. [CrossRef]

21. Gamba, M.; Pellegrino, G.; Cupertino, F. Optimal number of rotor parameters for the automatic design of synchronous reluctance machines. In Proceedings of the ICEM 2014, Berlin, Germany, 2-5 September 2014. [CrossRef]

22. Dziechciarz, A.; Martis, C. New shape of rotor flux barriers in synchronous reluctance machines based on Zhukovski curves. In Proceedings of the 9th ATEE 2015, Bucharest, Romania, 7-9 May 2015. [CrossRef]

23. Dziechciarz, A.; Oprea, C.; Martis, C. Multi-physics design of synchronous reluctance machine for high speed applications. In Proceedings of the IECON 2016, Florence, Italy, 23-26 October 2016. [CrossRef]

24. Credo, A.; Fabri, G.; Villani, M.; Popescu, M. High speed synchronous reluctance motors for electric vehicles: A focus on rotor mechanical design. In Proceedings of the 2019 IEMDC, San Diego, CA, USA, 12-15 May 2019. [CrossRef]

25. Ragazzo, P.; Ferrari, S.; Rivière, N.; Popescu, M.; Pellegrino, G. Efficient multiphysics design workflow of synchronous reluctance motors. In Proceedings of the 2020 ICEM, Gothenburg, Sweden, 23-26 August 2020.

26. Sanada, M.; Hiramoto, K.; Morimoto, S.; Takeda, Y. Torque ripple improvement for synchronous reluctance motor using an asymmetric flux barrier arrangement. IEEE Trans. Ind. Appl. 2004, 40, 1076-1082. [CrossRef]

27. Bianchi, N.; Bolognani, S.; Bon, D.; Dai Pre, M. Rotor flux-barrier design for torque ripple reduction in synchronous reluctance and PM-assisted synchronous reluctance motors. IEEE Trans. Ind. Appl. 2009, 45, 921-928. [CrossRef]

28. Davoli, M.; Bianchini, C.; Torreggiani, A.; Immovilli, F. A design method to reduce pulsating torque in PM assisted synchronous reluctance machines with asymmetry of rotor barriers. In Proceedings of the IECON 2016, Florence, Italy, 23-26 October 2016. [CrossRef]

29. Ferrari, S.; Pellegrino, G.; Davoli, M.; Bianchini, C. Reduction of torque ripple in synchronous reluctance machines through flux barrier shift. In Proceedings of the 2018 ICEM, Alexandroupoli, Greece, 3-6 September 2018. [CrossRef]

30. Credo, A.; Villani, M.; Popescu, M.; Riviere, N. Synchronous reluctance motors with asymmetric rotor shapes and epoxy resin for electric vehicles. In Proceedings of the 2019 IEEE ECCE, Baltimore, MD, USA, 29 September-3 October 2019. [CrossRef]

31. Bao, Y.; Degano, M.; Wang, S.; Chuan, L.; Zhang, H.; Xu, Z.; Gerada, C. A novel concept of ribless synchronous reluctance motor for enhanced torque capability. IEEE Trans. Ind. Electr. 2020, 67, 2553-2563. [CrossRef]

32. Babetto, C.; Bacco, G.; Bianchi, N. Synchronous reluctance machine optimization for high-speed applications. IEEE Trans. Energy Convers. 2018, 33, 1266-1273. [CrossRef]

33. Rizzi, L.; Zanocchi, G.; Rubino, A.; Castagnaro, E. Reluctance synchronous electric motor without magnets solution for e-mobility: A possible workflow for a quick and accurate design and optimization. In Proceedings of the IECON 2019, Lisbon, Portugal, 14-17 October 2019. [CrossRef]

34. Wu, H.; Depernet, D.; Lanfranchi, V.; El-Kadri-Benkara, K.; Azri Hizami Rasid, M. A novel and simple torque ripple minimization method of synchronous reluctance machine based on torque function method. IEEE Trans. Ind. Electr. 2021, 68, 92-102. [CrossRef]

35. Bobba, D.; Bramerdorfer, G.; Ding, H.; Silber, S.; Sarlioglu, B. Synchronous reluctance rotor design considerations based on winding configuration. In Proceedings of the 2019 IEEE ECCE, Baltimore, MD, USA, 29 September-3 October 2019. [CrossRef]

36. Stipetic, S.; Zarko, D.; Cavar, N. Adjustment of rated current and power factor in a synchronous reluctance motor optimally designed for maximum saliency ratio. IEEE Trans. Ind. Appl. 2020, 56, 2481-2490. [CrossRef]

37. Vartanian, R.; Toliyat, H.A.; Akin, B.; Poley, R. Power factor improvement of synchronous reluctance motors (SynRM) using permanent magnets for drive size reduction. In Proceedings of the 2012 IEEE APEC, Orlando, FL, USA, 5-9 February 2012. [CrossRef]

38. Uberti, F.; Frosini, L.; Szabó, L. An optimization procedure for a synchronous reluctance machine with fluid shaped flux barriers. In Proceedings of the 2020 ICEM, Gothenburg, Sweden, 23-26 August 2020. [CrossRef]

39. CEDRAT. User Guide Flux®11.2; CEDRAT: Meylan, France, 2013. 
40. Szabó, L.; Ruba, M. Using co-simulations in fault tolerant machine's study. In Proceedings of the ECMS 2009, Madrid, Spain, 9-12 June 2009. [CrossRef]

41. Uberti, F. Definition of a Rotor Geometry Optimization Procedure for a Synchronous Reluctance Machine. Master's Thesis, University of Pavia, Pavia, Italy, 24 September 2019.

42. Pyrhonen, J.; Jokinen, T.; Hrabovcova, V. Design of Rotating Electrical Machines, 2nd ed.; Wiley: Hoboken, NJ, USA, 2014.

43. Matsuo, T.; Lipo, T.A. Rotor design optimization of synchronous reluctance machine. IEEE Trans. Energy Convers. 1994, 9, 359-365. [CrossRef]

44. Lubin, T.; Razik, H.; Rezzoug, A. Maximum torque to current control of a synchronous reluctance machine by including cross-magnetisation. In Proceedings of the ICEM 2004, Cracow, Poland, 5-8 September 2004.

45. Hudak, P.; Hrabovcova, V.; Rafajdus, P. Geometrical dimension influence of multi-barrier rotor on reluctance synchronous motor performances. In Proceedings of the SPEEDAM 2006, Taormina, Italy, 23-26 May 2006. [CrossRef] 